\title{
The "disinhibition" of extinguished operant behavior in pigeons: Trial-tempo shifts and novel stimulus effects*
}

\author{
ELIOT HEARST, STANLEY R. FRANKLIN, and CONRAD G. MUELLER \\ Indiana University, Bloomington, Indiana 47401
}

\begin{abstract}
After conditioning and extinction of keypecking with 25-sec intertrial intervals between key illuminations, an immediate change to 5 -sec intertrial intervals reinstated pecking during trials. Brief illuminations of the chamber during intertrial intervals also temporarily restored extinguished keypecking. The same manipulations of trial tempo and chamber illumination usually weakened well established, still reinforced keypecking. No recovery of extinguished behavior occurred when the intertrial interval was shifted upward from $5 \mathrm{sec}$ to $25 \mathrm{sec}$. These and other behavioral findings were examined in relation to (a) Pavlov's and Skinner"s research and views on "disinhibition" and "external inhibition" and to (b) analogous phenomena in physiological studies of habituation and dishabituation. The reliable evidence of disinhibition obtained in the present experiments suggests the involvement of an inhibitory process in extinction.
\end{abstract}

Disinhibition refers to the temporary reinstatement of an extinguished CR when an extraneous stimulus is presented (Pavlov, 1927). Demonstrations of this phenomenon, as well as the phenomenon of spontaneous recovery, helped convince Pavlov that an active inhibitory process is involved in the loss of a CR during extinction; extinction does not erase the excitation established by prior reinforcement, but builds up an inhibitory force that counteracts the excitation present in the situation. Furthermore, he viewed disinhibition as the "inhibition of an inhibition" rather than as the addition of some new excitatory effect to the situation. In support of the former alternative, he demonstrated that the same extraneous stimuli which produce disinhibition of an extinguished $\mathrm{CR}$ would usually decrease a well established and still reinforced CR ("external inhibition").

Most experimental examples of disinhibition have been obtained with Pavlovian conditioning procedures. Skinner (1938) tried but was unable to demonstrate disinhibition of operant behavior (for example, by tossing rat $S s$ in the air during extinction of leverpressing). Similarly, Boakes (1973) was unsuccessful in his attempts to use a flashing light to disinhibit extinguished keypecking in pigeons. Skinner believed that evidence of disinhibition in operant conditioning would bolster the argument of other workers that a concept of inhibition is needed in analyzing behavior. His failure to obtain disinhibition was one of the reasons he concluded that inhibitory processes need not be postulated.

\footnotetext{
*This research was supported by National Institute of Mental Health Grant $\mathrm{MH}-19300$. We thank Dexter Gormley for valuable advice and assistance. Some of these experiments were presented at the annual meeting of the Psychonomic Society, St. Louis, 1972. Requests for reprints should be sent to Fliot Hearst, Psychology Department, Indiana University, Bloomington, Indiana 47401.
}

However, several recent rat experiments involving extraneous lights and sounds produced convincing disinhibition of operant behavior (see Boakes \& Halliday, 1972; Brimer, 1970a). The present set of experiments, which employed pigeons in a standard keypecking situation, yielded some effects that, at least on the surface, appear to be of a similar kind.

We originally set out to determine whether effects analogous to those obtained in some neurophysiological studies of habituation would occur in a behavioral test situation. Information of this kind might, in our opinion, broaden the experimental base for evaluating the role of inhibition in behavior. The neurophysiological work involved manipulations of the frequency of repeated stimulation (see Horn \& Hinde, 1970, and Thompson \& Spencer, 1966, for extended discussions). For example, in recording from postsynaptic sites, Bruner and Kennedy (1970) found that habituated evoked potentials at neuromuscular junctions in the crayfish could be reinstated not only by a period of several minutes without stimulation but also by increases in stimulus frequency. To perform an analogous manipulation in a behavioral (operant) situation, we increased the rate of trial presentations (5-sec key illuminations) after a pigeon's keypecking had been conditioned and extinguished with relatively inf requent trials. Once recovery of extinguished behavior by such a temporal manipulation had been reliably demonstrated, we investigated several factors that might affect the magnitude of recovery and several alternative explanations for it [e.g., Sokolov's (1963) neuronal discrepancy hypothesis, various types of interaction between excitatory and inhibitory effects]. In the course of analyzing the behavioral recovery produced by massing of trials, we (a) inserted other kinds of events (5-sec chamber illuminations) in place of the extra trials during extinction and (b) determined whether trial 
massing had a facilitative or reductive ("external inhibitory") effect on reinforced responses.

\section{GENERAL METHOD}

\section{Subjects}

Experimentally naive female White Carneaux pigeons, 5 to 7 years old, served in all the studies. Throughout their participation in an experiment, Ss were maintained at approximately $75 \%$ of their free-feeding weights. Water was available in their individual home cages at all times.

\section{Apparatus}

A standard Lehigh Valley Electronics pigeon test chamber was employed. The response key (in the center of the front panel) was illuminated during trials by a black vertical line on a white background. Except for Experiments IV and V, in which a houselight came on intermittently during test sessions, the chamber was completely dark between trials; the only illumination of the chamber occurred when the key was lighted during trials or the feeder lamp was turned on during reinforcement ( $3 \mathrm{sec}$ of grain).

Electromagnetic counters recorded various stimulus, response, and reinforcement measures. A printout counter provided trial-by-trial counts of keypecks during test sessions. Gerbrands or Scientific Prototype cumulative recorders supplied continuous records of keypecking behavior for each experimental session. The relay circuitry and recording equipment were located in a room adjoining the experimental cubicle. External sounds were masked by a continuous white noise in the experimental cubicle and by an air blower in the test chamber.

\section{Procedure}

Experimental sessions occurred 7 days a week. After being trained to eat grain from the magazine, all birds were hand shaped to peck the constantly illuminated key. The Ss then received 60 continuous reinforcements (CRF) for pecking the key during two to three daily sessions. On the next day, Ss were placed on a discrete trial 5 -sec fixed-interval (FI) reinforcement schedule, that is, the first response after the keylight had been on for $5 \mathrm{sec}$ terminated the keylight and produced grain. The intertrial interval (ITI) was either $5 \mathrm{sec}$ or $25 \mathrm{sec}$, depending on the experiment. The Ss received three sessions on this procedure, 60 trials per session, with reinforcement available following each trial. For the next seven sessions Ss were placed on a $50 \%$ reinforcement schedule; only 30 (randomly selected) of the 60 daily trials ended with reinforcement.

In the various experiments described below, different groups of birds received tests, either during continuation of the above procedure with reinforcement or under extinction procedures. The primary variables of concern were (a) changes in the tempo at which trials were presented, i.e., variations of the ITI, and (b) the type of event occurring during the period between regular trials (5-sec illuminations of the houselight were presented during the ITI in Experiments IV and V). The details of these test procedures will be described separately for each experiment.

\section{EXPERIMENT I: DEMONSTRATION OF "DISINHIBITION" BY TRIAL-TEMPO SHIFTS}

Our first experiment was an attempt to determine whether substantial recovery of an extinguished operant would occur if trial frequency were increased after cessation of responding. In pilot studies we had of ten obtained an effect of this kind in relatively sophisticated Ss under a variety of procedures and in several unrelated experiments. In that work a revival of extinguished behavior seemed most likely to occur when trial onsets throughout the experiment were very "salient," i.e., when they involved gross changes in chamber illumination or auditory stimulation. Because of this general observation, key illumination trials were presented in a chamber that remained dark between trials throughout acquisition and extinction in Experiment $I$ and under the regular conditions of subsequent experiments. Once a revival of extinguished behavior had been reliably demonstrated in naive Ss, we could then analyze factors affecting the phenomenon and consider several alternative explanations for it (Experiments II-V).

\section{Method}

Procedure. For all 10 Ss the ITI throughout acquisition was $25 \mathrm{sec}$. One S (S 1552) had a blank white field projected on the key during FI trials, but all the other Ss had the standard display with the vertical line. On the day following the seventh session on the $50 \%$ reinforcement schedule, a single test session was given in which all birds were first extinguished with trials separated by $25-\mathrm{sec}$ ITIs; then 5-sec ITIs were introduced.

On this test day, before the onset of extinction, Ss received 10 warm-up trials, 5 of which ended in reinforcement (as during the immediately preceding 7 days). All reinforcement was eliminated for the rest of the session and each presentation of the keylight lasted exactly $5 \mathrm{sec}$. Keypecking was extinguished to a criterion of five consecutive trials without a response (5NR criterion).

Up to this point, throughout training and extinction, the trials had been spaced at 25 -sec intervals. As soon as $S$ reached the $5 \mathrm{NR}$ criterion, however, the ITI was shifted to $5 \mathrm{sec}$. Although we had selected the 5-sec and 25 -sec values on the basis of preliminary experiments, we had no firm basis for deciding how long to continue exposure to the changed ITI. Therefore, for the first two Ss run (the top two records in Fig. 1) the blocks of different ITIs did not alternate automatically but were changed by $\mathrm{E}$ as he monitored the test session and observed S's behavior. He shifted to the other ITI value whenever keypecking seemed to have ceased at one value. Subsequently, a standard procedure was adopted and used for the other eight Ss: The 5-sec ITI was maintained for a 3-min block of trials, then it was shifted back to $25 \mathrm{sec}$ for $3 \mathrm{~min}$, then back to $5 \mathrm{sec}$ for $3 \mathrm{~min}$, etc.

\section{Results and Discussion}

Cumulative response curves for each $\mathrm{S}$ are presented in Fig. 1. To save space, all records are arranged to begin with the occurrence of the first of the five nonresponse trials required to reach the $5 \mathrm{NR}$ criterion; thus, there is no responding on any of the five trials separated by 25 -sec ITIs at the extreme left of each record. Eight of the 10 Ss showed a large recovery of behavior in the first block of 5-sec ITIs and all 10 Ss made their first post-5NR response during a block of 5-sec ITIs. Several Ss showed additional recovery on later blocks of 5-sec ITIs.

As noted, all post-5NR responding began during 5 -sec ITI blocks. This is a fact to be stressed, because our final selection of a fixed block duration was such that a few examples of response "spillover" from 5-sec blocks into 25 -sec blocks apparently occurred. A similar outcome was not present in the records of the first two birds; for these Ss a relatively long period of nonresponding in one ITI block provided the basis for $\mathrm{E}$ to switch to the other 


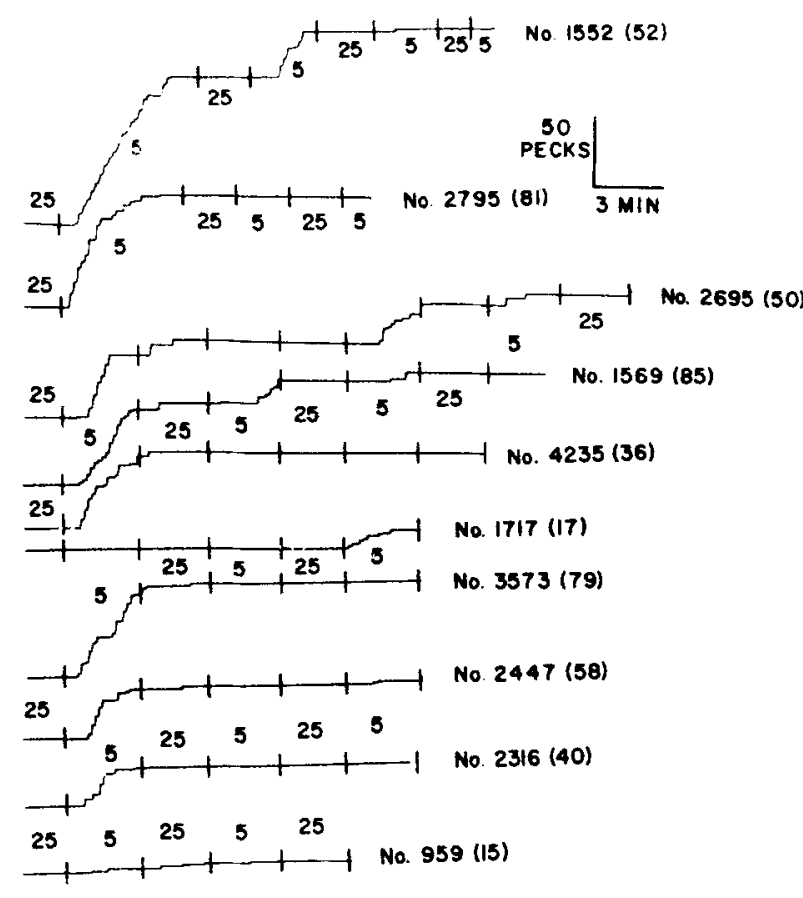

Fig. 1. Cumulative response curves for 10 pigeons previously conditioned and then extinguished with 25 -sec ITIs. The curves begin with attainment of the $5 \mathrm{NR}$ extinction criterion under 25-sec ITIs. Thereafter, periods of 5-sec ITIs and 25-sec ITIs alternated, but all responding continued to be nonreinforced. Individual bird numbers are given at the right of each record; in parentheses is the number of trials $S$ required to reach the $5 \mathrm{NR}$ criterion (inchuding the five criterion trials).

ITI. In neither bird was there any responding in 25 -sec blocks. The question of spillover effects will arise in connection with our later experiments, all of which used a predetermined block length in order to facilitate automatic programming of the procedure and to insure uniform treatment of all Ss.

Since clear-cut recovery occurred in every $S$ tested in this experiment, with the possible exception of S 959 , we felt we had developed a good "preparation" for studying response recovery following extinction in an operant situation.

\section{EXPERIMENT II: EQUALTIME VS EQUAL-TRIALS TESTS}

Experiment I convincingly demonstrated that an increase in trial tempo would reinstate extinguished operant behavior. In a more extensive experiment, we next compared several variations of the Experiment I testing procedure in order to evaluate the generality of the recovery phenomenon and to isolate some of the factors responsible for it. Therefore, in Experiment II recovery of extinguished behavior was examined (a) over a larger number (10) of alternated 5-vs 25 -sec extinction blocks; (b) with equal numbers of trials (12) during the 5- vs 25 -sec blocks, as compared to equal amounts of time (2 min) per block; (c) in "control" Ss that never received 5-sec ITIs during extinction but were merely maintained on 25 -sec ITIs for 120 trials beyond the 5NR criterion. Results obtained from this control group would tell us the likelihood of response recovery following attainment of the 5NR criterion, even if no 5 -sec ITIs were presented.

\section{Method}

Procedure. Until the final (test) session, all 19 Ss were exposed to the same treatment as the $S s$ in Experiment I. After reaching the $5 \mathrm{NR}$ criterion, however, each $\mathrm{S}$ received one of three possible types of tests for response recovery during continued extinction: (1) alternating blocks of 125 -sec ITIs and 12 25-sec ITIs ("equal-trials" condition, $\mathrm{N}=8$ ); (2) alternating 2-min blocks of 5-sec ITIs and 25-sec ITIs ("equal-time" condition, $\mathrm{N}=5$ ); (3) 120 further trials of extinction with the $25-\mathrm{sec}$ ITI ("control" condition, $\mathrm{N}=6$ ). The equat-trials and equal-time groups were both given 10 blocks of each type of ITI; the former group thus received a total of 240 trials after the $5 \mathrm{NR}$ criterion had been met and the latter a total of 160 trials (i.e., 120 5-sec ITIs and 4025 -sec ITIs).

\section{Results and Discussion}

The effects of the different procedures instituted after attainment of the 5NR extinction criterion are shown in Fig. 2. The first two blocks of 5-sec ITIs in either the equal-trials or equal-time groups yielded approximately three to six times as many trial keypecks as occurred during the first 24 trials under 25-sec ITIs. This facilitation of behavior was also obvious when the first two blocks of trials separated by 5-sec ITIs were compared to the first 24 trials in the control group, which received no 5 -sec ITIs at all.

The curves for the 5-sec ITIs remained slightly above the 25-sec curves in the equal-trials and control groups on the second two blocks of trials (Trials 25-48), but the effects of the 5- vs 25 -sec ITI blocks did not differ

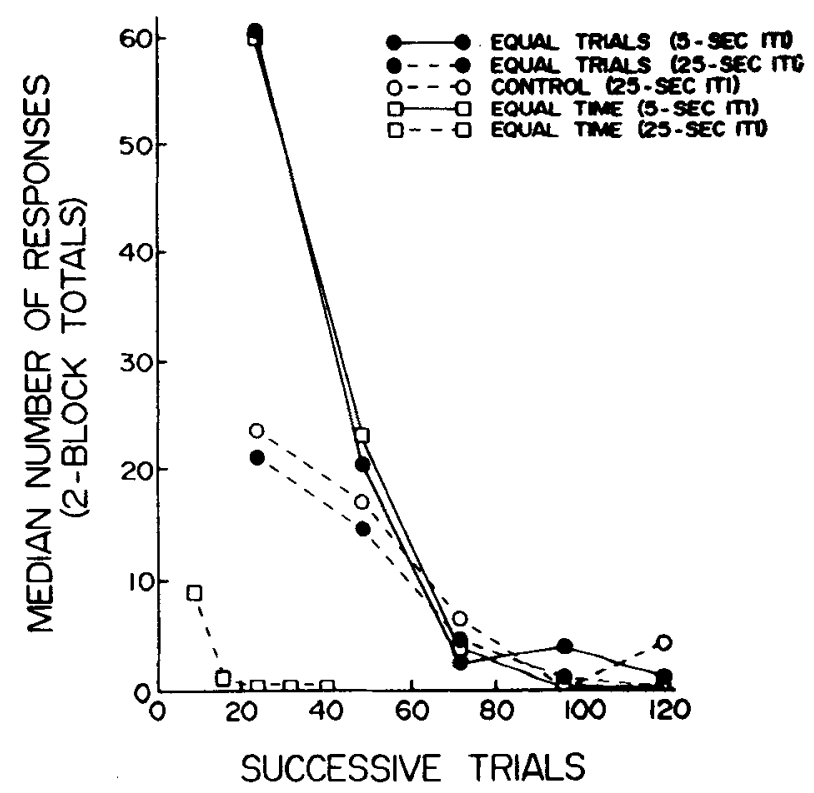

Fig. 2. Median two-block total responses over successive trials of testing in extinction with either 5- or 25-sec ITIs. All birds had reached the 5NR extinction criterion under 25-sec ITIs just prior to testing with the different ITIs. 
systematically for the remainder of the test. This disappearance of the facilitative effects of 5-sec ITIs resembles the habituation of dishabituation reported in physiological studies (Thompson \& Spencer, 1966).

Data for individual $S s$ in the equal-trials group revealed that seven of the eight Ss showed at least $29 \%$ more responding during the first two blocks of 5-sec ITIs than during the first two blocks of 25-sec ITIs. One S was anomalous and responded more during the first two 25 -sec ITI blocks than during the first two 5 -sec blocks ( 85 vs 48 responses). Over the entire 10-block test, seven of the eight Ss responded more during 5-sec ITI blocks than during 25-sec blocks; the one S giving the opposite result (the above "anomalous" S) made only slightly more responses on 25-sec blocks than on 5-sec blocks (209 vs 204 responses). Over the entire test there were 921 responses made on $5-\sec$ blocks and 527 responses on 25 -sec blocks for all Ss combined $(t=2.57, \mathrm{df}=7$, $p<.05$ by a $t$ test for correlated means).

In the equal-time group, a comparison of total responses on trials separated by $5-\mathrm{sec}$ vs $25 \cdot \mathrm{sec}$ ITIs during the first 24 trials on each (two blocks for the 5-sec ITIs, six blocks for the 25-sec ITIs) indicated at least 55\% greater responding on the 5-sec blocks for four of the five Ss. The other S did not start responding until the fourth block of trials; during that block it made 45 responses on the 12 trials separated by 5 -sec ITIs and only 8 responses on the 4 trials separated by $25-\mathrm{sec}$ ITIs. Over the entire test all five Ss responded more during 5 -sec than 25-sec blocks; to take into account the unequal number of trials on 5- and 25 -sec blocks, the actual response outputs on 25 -sec blocks were multiplied by 3 . With this correction, there were a total of 626 responses made by all Ss on 5-sec blocks and 378 responses on 25 -sec blocks $(t=3.85, \mathrm{~d} f=4, \mathrm{p}<.02)$.

In terms of number of trials required in extinction before attainment of the $5 \mathrm{NR}$ criterion, $\mathrm{Ss}$ in the equal-trials, equal-time and control groups did not differ significantly. The median number of trials required to reach the criterion were 58.5, 63.0, and 62.0, respectively, in the three groups. In Experiment $I$ the median had been 51.0 trials for the $10 \mathrm{Ss}$, not significantly different from the values obtained from the Ss in Experiment II.

Several additional details of the trial-tempo effect are worthy of mention. In some Ss a clear-cut revival of responding did not occur during the first block of 5 -sec trials but during a later block (usually the second). That is one of the reasons we combined blocks in Fig. 2 and performed statistical tests on the data for the entire test. However, such a treatment of the results masks the fact that individual Ss generally did not begin keypecking immediately after the shift to a faster trial tempo. Most often, at least five or six trials without a response passed after the introduction of 5-sec ITIs, i.e., Ss usually did not start responding until the latter part of the first test block (cf. Fig. 1). A lag before recovery has also been observed in neurophysiological studies in which high-frequency stimulation restored habituated evoked potentials (Bruner \& Kehoe, 1970).

Another detail of individual performance that is not revealed in the group data of Fig. 2 is the fact that keypecking on 25 -sec ITI blocks occurred mainly at the beginning of these blocks. This effect could be described as a spillover from responding initiated toward the end of 5-sec ITI blocks-a phenomenon also mentioned in connection with Experiment I. Such spillover would act to decrease the absolu te magnitude of response recovery, as we have discussed it above in terms of a difference between 5 - and 25 -sec trial blocks.

Nevertheless, in virtually all the comparisons made in this experiment and in Experiment I, responding was appreciably more frequent on trials separated by $5-\mathrm{sec}$ ITIs than on trials separated by 25 -sec ITIs, after acquisition and extinction with 25-sec ITIs. Was this effect attributable to the "novelty" of 5-sec ITIs during extinction, i.e., to some discrepancy between S's established code or neural model of the details of its previous experimental treatment and the new ITI value presented during the test (see Sokolov, 1963)? One way of evaluating this discrepancy notion is to see whether a revival of responding will occur when Ss are shifted to 25-sec ITIs after exposure to 5-sec ITIs during acquisition and initial extinction (the reverse of the procedure used in the first two experiments). This rationale guided the design of Experiment III.

\section{EXPERIMENT III: INITIAL EXTINCTION WITH SHORT ITIs}

In Experiment III two groups of Ss were extinguished to the 5NR criterion with 5-sec ITIs and then given a test sequence like that of the equal-trials group in Experiment II. One group in Experiment III had previously received acquisition with $25-\mathrm{sec}$ ITIs and the other with 5-sec ITIs. If a mere change or discrepancy in ITI were responsible for the recovery of extinguished behavior in Experiments I and II, then the group trained and initially extinguished on 5-sec ITIs ought to show recovery when $25-\mathrm{sec}$ ITIs are instituted during extinction. Furthermore, one might expect more "spontaneous recovery" to occur if the ITI was lengthened after initial extinction than if it was shortened, as in Experiments I and II. That expectation might provide another reason for predicting more responding on 25 -sec ITI blocks than on 5-sec blocks in Experiment III.

The other group, trained with 25-sec ITIs and extinguished to $5 \mathrm{NR}$ with 5 -sec ITIs, should help us to decide whether any facilitative effects obtained when testing the first group with 25-sec ITIs were due to the ITI shift occurring during the extinction session itself or to the ITI shift compared to the conditions prevailing during acquisition. 


\section{Method}

Procedure. Although all 16 Ss were extinguished to the 5NR criterion with 5-sec ITIs in this experiment, half of them had been initially trained with $25-\mathrm{sec}$ ITIs and half with 5 -sec ITIs. Otherwise, the acquisition conditions were identical to those in Experiments I and II. On the test day, Ss first received a 10-trial warm-up with $50 \%$ reinforcement under the ITI in effect during acquisition and were then extinguished under 5-sec ITIs until they attained the $5 N R$ criterion. Subsequently, each $S$ received 10 alternating blocks of $1225-\mathrm{sec}$ ITIs and 125 -sec ITIs, i.e., the equal-trials test procedure of Experiment II was in force, except, of course, that the first block of test trials involved a shift to 25-sec ITIs rather than to 5-sec ITIs.

\section{Results and Discussion}

Figure 3 summarizes the results of Experiment III. Rather than producing a recovery of extinguished behavior, the introduction of $25-\mathrm{sec}$ ITIs generally led to less trial responding than occurred on 5-sec ITI blocks-the ITI value that had been present during initial extinction for both groups in Fig. 3. In the group both trained and initially extinguished with 5-sec ITIs (Fig. 3, left-hand set of curves), six of the eight Ss emitted more keypecks on trials separated by 5 -sec than by 25 -sec ITIs over the first two blocks of testing; the other two Ss did not respond at all during the first two blocks of either kind of ITI. Over the entire test for all eight Ss, 335 responses were made during 5 -sec ITI blocks and 178 responses during $25-\mathrm{sec}$ blocks $(\mathrm{t}=2.33, \mathrm{df}=7, \mathrm{p}$ just fails to reach the .05 level of confidence). The absolute level of responding during the test was much lower than in Experiment II, presumably because response strength during 5-sec ITI blocks (which facilitated extinguished behavior in Experiment II) had already been greatly reduced by the extinction given at that ITI before the test sequence began.

In the group that received acquisition with 25 -sec ITIs and initial extinction to $5 \mathrm{NR}$ with 5-sec ITIs, there was also more responding on 5-sec ITI blocks than on 25-sec blocks, but the differences were not statistically significant and were much smaller than in all the experiments mentioned thus far. For all eight Ss combined over the entire test, 957 responses were emitted on 5 -sec blocks and 664 on 25 -sec blocks $(\mathrm{t}=1.51, \mathrm{df}=7, \mathrm{p}>.10)$. Absolute response levels were generally higher in this group than in the other panel of Fig. 3, the latter group involving Ss both trained and extinguished with 5-sec ITIs.

The results of Experiment III indicate that the differences in extinction responding between 5 - and 25 -sec blocks in Experiments I and II were not the mere consequence of a "change" in the ITI from acquisition and/or extinction to testing; within a test period, responding without reinforcement was generally greater on $5-\mathrm{sec}$ than $25-\mathrm{sec}$ blocks regardless of prior acquisition and extinction conditions. Therefore, one can question whether the effects we obtained are really examples of "disinhibition," a term that is usually applied to response recoveries produced by novel (extraneous) stimuli. In fact, when adopting an analog to the Bruner and Kennedy (1970) experimental procedure as the paradigm for Experiments I-III, we were explicitly looking for other ways of reinstating extinguished behavior. If one takes the view that any measure of momentary response strength is the resultant of some plus factor (e.g., "excitation") and some minus factor (e.g., "inhibition"), then increases in behavior can arise in at least three distinctive ways: (1) inhibition may dissipate as a function of time (an example would be spontaneous recovery), (2) some additional excitatory effect may be added that overrides the inhibition, and (3) inhibition may itself be inhibited. Analysis of physiological measures in Bruner and Kennedy's work demonstrated that a mechanism of Type 2 was responsible for the recovery of habituated evoked potentials they observed when stimulation frequency was increased.

The results of Experiments I-III seemed interpretable within a framework employing opposed processes, such as excitation-inhibition, but did not warrant an "inhibition of an inhibition" explanation (Type 3 above). The asymmetrical results of Experiments II and III (recovery with a trial-tempo shift in one direction but not in the other) are more simply handled by positing some excitatory effect of 5 -sec ITIs as compared to 25-sec ITIs, a conclusion analogous to that of Bruner

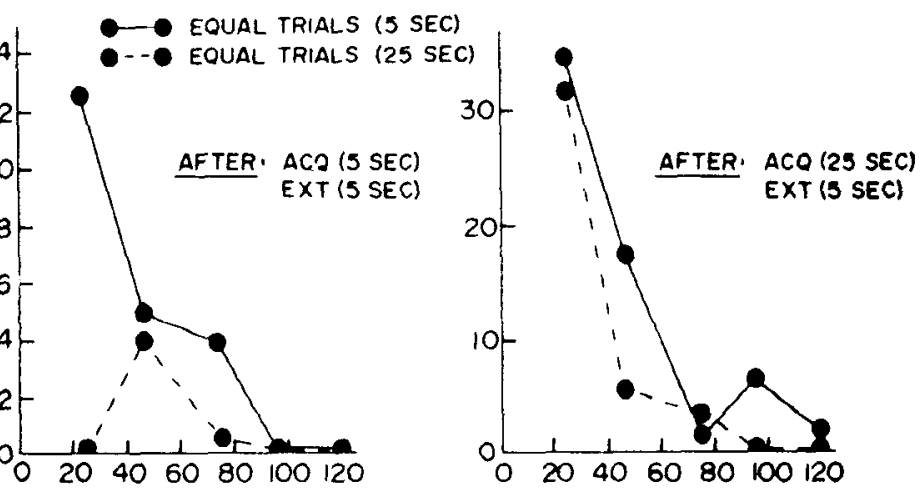

Fig. 3. Median two-block total responses over successive trials of testing in extinction with either 5- or 25-sec ITIs. All birds had reached the 5NR extinction criterion under 5 -sec ITIs just prior to testing with the different ITIs. However, the curves on the left were obtained from Ss conditioned with 5 -sec ITIs and on the right from Ss conditioned with 25-sec ITIs. 
and Kennedy. In our next experiment, we selected an "extraneous" visual stimulus, one that did not itself evoke directed keypecking behavior and had not previously been associated with reinforcement, and tested its effects on extinguished behavior under a procedure as similar as possible to the trial-tempo manipulation of the prior experiments.

\section{EXPERIMENT IV: HOUSELIGHT INSERTIONS VS ITI SHIFTS AFTER EXTINCTION}

For use as an extraneous stimulus we wanted to employ a novel visual stimulus that did not generalize greatly with the keylight stimulus and would probably not produce pecking responses. Houselight illumination seemed appropriate, since it came from a different location than the keylight, involved a relatively diffuse source of (dim) light, and was not expected to evoke directed behavior. Stated briefly, in Experiment IV we trained and extinguished Ss under 25-sec ITIs and then presented $5-\mathrm{sec}$ illuminations of the houselight in place of the two $5-\mathrm{sec}$ trials that occurred between regular trials (i.e., those separated by $25 \mathrm{sec}$ ) during the 5 - $\mathrm{sec}$ ITI blocks in prior experiments.

Presentations of a novel, extraneous visual stimulus like the illumination of a houselight resemble, more than do trial-tempo variations, the type of test stimulus used in Pavlov's (1927) and Brimer's (1972) experiments on disinhibition. By employing such a stimulus, we could determine whether effects similar to theirs would be obtained in pigeons. ${ }^{1}$

\section{Method \\ Procedure. After acquisition and initial extinction to the 5 NR criterion under the same conditions as in Experiments I and II (i.e., 25-sec ITIs were in force throughout), all 16 Ss received two kinds of subtests during the remainder of the test session, with continued nonreinforcement of keypecking. One subtest involved five alternated blocks of 125 -sec and 1225 -sec ITIs (like the previous experiments), whereas the other subtest involved five alternated blocks of 12 trials during which (a) 5-sec illuminations of the houselight occurred every $5 \mathrm{sec}$ during regular 25-sec ITIs or (b) no illuminations of the houselight occurred during the regular 25-sec ITIs. According to this procedure, an ITI in Condition a would successively consist of $5 \mathrm{sec}$ of darkness, $5 \mathrm{sec}$ of houselight, $5 \mathrm{sec}$ of darkness, $5 \mathrm{sec}$ of houselight, and $5 \mathrm{sec}$ of darkness. Ther efore, illuminations of the houselight occurred in the same temporal position as the added trials given when 5 -sec ITIs were in effect in the other subtest. The houselight was a 2.8 -W G.E. 1820 bulb, located $7.5 \mathrm{~cm}$ above the key and shielded from direct view, which dimly illuminated the interior of the chamber. Ten birds received the 5- vs 25 -sec ITI subtest first and then the houselight vs no-houselight subtest, whereas six other Ss received these subtests in the reverse order.}

\section{Results and Discussion}

Figure 4 summarizes the data from this experiment. Results from the two subtests are combined for a given condition, since the major conclusions were the same regardless of whether that subtest occurred first or second. Presentations of two 5-sec houselights during the 25-sec ITIs led to a substantial recovery of extinguished behavior, appreciably greater and more consistent than that produced by a shift to $5-\mathrm{sec}$ ITI blocks. As expected, no $S$ ever pecked the unlit key during illuminations of the houselight. Periodic observations of Ss by $\mathrm{E}$ also indicated that they did not peck at or near the houselight either.

Twelve of the 16 Ss responded more during 5-sec ITI blocks than during 25 -sec blocks on the ITI-shift subtest. These results corroborate the findings of Experiments I and II, although the extent of the trial-tempo effect was smaller than in the prior experiments. Five of the six Ss that received the houselight subtest before the ITI subtest responded more during blocks with interpolated houselights than during no-houselight blocks (412 total responses during trials preceded by houselights and only 134 during trials not preceded by houselights $)(t=2.74$, $\mathrm{df}=5, \mathrm{p}<.05$ ). Eight of the $10 \mathrm{Ss}$ given the houselight subtest second showed a difference in the same direction (417 total responses during trials preceded by houselights and 140 during trials not preceded by houselights $)(\mathrm{t}=3.40, \mathrm{df}=9, \mathrm{p}<.01)$.

This experiment demonstrated a recovery of extinguished behavior that resulted from presentations of a novel external stimulus ${ }^{2}$ which itself did not evoke directed pecking behavior. The fact that a discrete external stimulus was used to reinstate extinguished behavior makes this result more similar to prior reports of disinhibition than were our findings with trial-tempo shifts. However, unlike many of Pavlov's (1927) and Brimer's (1970a, 1972) examples of disinhibition, the revival of responding did not occur during the novel stimulus itself but some seconds afterward. Of course, pecking in pigeons rarely occurs to an unlit key after training with a lighted key, and this may have prevented any overt expression of Ss tendency to peck during houselight illuminations.

\section{EXPERIMENT V: HOUSELIGHT INSERTIONS VS ITI SHIFTS DURING ACQUISITION}

After acquisition and extinction with 25-sec ITIs, the introduction of either extra trials or houselight illuminations within the regular 25-sec ITIs reinstated extinguished behavior (Experiments I, II, and IV). Do both these findings reflect the addition of some general excitatory effect produced by the frequent trials or houselight presentations? Perhaps these manipulations "heighten S's activity" or "arouse" $S$ so that dominant behaviors in the situation are sensitized or facilitated (see Thompson \& Spencer, 1966). As noted earlier, the asymmetry between the trial-tempo results of Experiments II and III implicated the addition of an excitatory effect, rather than the inhibition of an inhibition, as an explanation of the obtained response recoveries. 
One way of evaluating these possibilities is to determine whether the same manipulations will also facilitate well established and still reinforced responses. One of Pavlov's major bases for his argument that two processes, excitation and inhibition, are needed to explain behavior was his finding that extraneous stimuli generally reduce well established CRs ("external inhibition") but increase extinguished behavior ("disinhibition"). How could these conflicting effects be resolved, he asked, unless two different processes were operating? In our final experiment we presented houselights within the ITI (or we shifted to another trial tempo) during continued $50 \%$ reinforcement of trial keypecking. If these manipulations increase well established responses, as they did extinguished responses, the most parsimonious account of all our reported effects might be framed in purely "excitatory" terms.

\section{Method}

Procedure. All seven Ss were exposed to standard acquisition procedures with 25 -sec ITIs separating keylight trials. Then (instead of a test in extinction, as was given all previous Ss) Ss were presented with houselight illuminations during continued $50 \%$ reinforcement of trial responding. A 10-trial warm-up with 25-sec ITIs began the test session; then three blocks of 10 trials with two houselight presentations inserted during each ITI were alternated with three blocks of 10 trials without houselights. Each houselight presentation lasted $5 \mathrm{sec}$ and occurred in the same temporal position relative to "trials" as did the extra keylight trials when the ITI was $5 \mathrm{sec}$ in prior experiments. A record was kept of whether or not a particular trial was reinforced so that we could later examine differences in the effect of houselight presentations depending on whether the immediately prior trial was reinforced or non reinforced.

After three additional sessions on the standard acquisition procedure with 25 -sec ITIs, a second test was given with $50 \%$ reinforcement. (Due to an error by $\mathrm{E}$, the test data were lost for one S.) After the usual 10-trial warm-up, three alter nating blocks of 105 -sec and 1025 -sec ITTs were administered.

\section{Results and Discussion}

When houselight illuminations were inserted during regular 25-sec ITIs, trial performance declined in comparison to blocks of trials without houselights. Six of the seven birds emitted fewer responses during houselight blocks. A total of 2,326 responses were made during no-houselight blocks and 2,160 during houselight blocks $(\mathrm{t}=2.91, \mathrm{df}=6, \mathrm{p}<.05)$. Thus, insertions of the houselight significantly reduced reinforced behavior in this experiment, whereas they had consistently and substantially increased extinguished behavior in Experiment IV. Pavlov's assertion that disinhibitors of extinguished behavior will usually act as external inhibitors of well established CRs was supported by these results (cf. Brimer, 1972, pp. 216-218).

Several interesting and perhaps very important subsidiary findings resulted from an analysis of trial responding as dependent on (a) whether the immediately prior trial had ended in reinforcement and (b) whether houselights had been inserted between the two trials. Over the entire test, on trials that followed ITIs without inserted houselights, Ss made a mean of 11.5

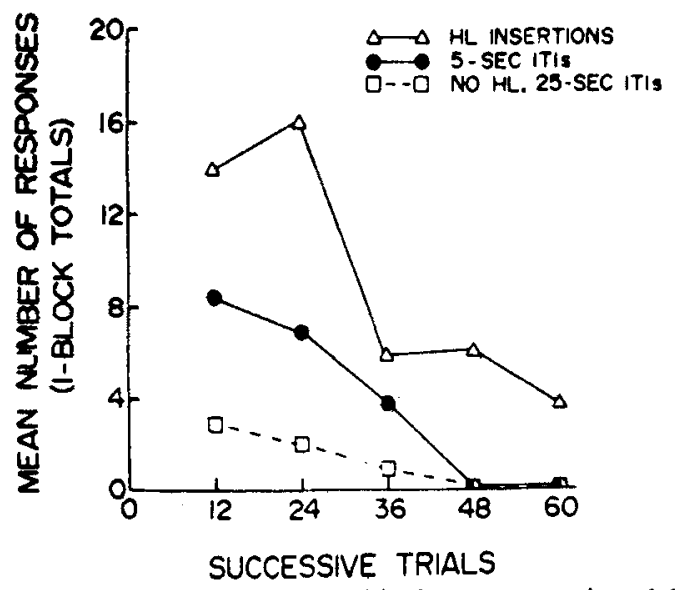

Fig. 4. Mean total responses per block over successive trials of testing in extinction with (a) two houselight (HL) presentations inserted during each 25-sec ITI, (b) 5-sec ITIs and no houselights between trials, or (c) 25 -sec ITIs and no houselights between trials. Condition $c$ was the one in force throughout acquisition and initial extinction to the $5 \mathrm{NR}$ criterion.

responses/trial if the prior trial had been reinforced and 12.0 responses/trial if it had not. Five of the seven Ss showed an effect in this direction, which resembles some of the frustration phenomena extensively analyzed by Amsel (1967; see also Scull's review and evaluation, 1973); in that research, behavior has generally been found to be stronger on trials following nonreinforced trials than after reinforced trials. On the other hand, on trials that followed ITIs with inserted houselights, Ss made a mean of 11.4 responses/trial if the prior trial had been reinforced and only 10.5 responses/trial if it had not. Statistical analysis showed that the interaction between houselight condition and prior-trial outcome was significant beyond the .05 level $(F=7.02, d f=1 / 6)$. Therefore, the inhibitory effect of houselight presentations mentioned in the last paragraph resulted from a response decrement on trials following nonreinforced trials; inserted houselights did not significantly affect responding on trials following reinforcement.

After three more acquisition sessions, six Ss were tested with blocks of 5- and 25-sec ITIs during continued $50 \%$ reinforcement of trial responding. A total of 1,990 responses were made by all Ss following 5-sec ITIs and 2,139 following 25-sec ITIs. However, the difference in total responses between the two conditions was not significant $(t=1.44, d f=5)$. There were eight cases of a decrease during 5-sec ITI blocks when each was compared to its immediately preceding 25 -sec block, and four cases of an increase. When compared to immediately following 25 -sec blocks, there were 11 cases of lower responding during 5 -sec blocks, 6 cases of higher responding, and 1 case of equal responding.

In summary, the introduction of 5-sec ITIs during continued reinforcement of behavior yielded results in the same direction as those obtained when houselights were presented: Baseline responding was, if anything, reduced (externally inhibited) by either change in procedure. Apparently, the substantial facilitative effects 
of these manipulations on extinguished responding (Experiments I-IV) cannot be explained by simply positing a general facilitatory effect of massed trials or inserted visual stimuli (which, for the trial-tempo effect, had been suggested by results of Experiments II and III).

\section{GENERAL DISCUSSION}

These experiments have demonstrated that extinguished operant behavior can be temporarily revived either by increases in the tempo at which trials are given or by the presentation of novel visual stimulation (brief houselight illuminations) during intertrial intervals. The houselight effects with pigeons, as well as results reviewed and obtained by Brimer (1972) with rats in both free responding and discrete-trial operant situations, fail to support Skinner's (1938) conclusion that extinguished operants cannot be restored by extraneous events. His experimental attempts to "disinhibit" operant behavior were unsuccessful, and he even questioned the reliability of the recovery phenomena reported by Pavlov in classical conditioning situations. However, the effects observed in the present research were robust and reliable.

The fact that houselight illuminations significantly decreased well established, still reinforced keypecking showed that such stimulation does not simply generate "facilitative," "excitatory," or "arousing" effects. It produces incremental or decremental effects depending on the conditions of response strength and reinforcement vs nonreinforcement prevailing at the time of its presentation. Pavlov used this kind of finding to justify his belief that two general processes, excitation and inhibition, interact in the control of behavior.

Let us examine our results in the light of Pavlov's type of analysis. Since he believed that the restoration of extinguished CRs by the presentation of extraneous stimuli resulted from the inhibition of an inhibition, Pavlov used the term "disinhibition" to refer to such revivals of responding; "external inhibition," on the other hand, referred to the weakening of well established CRs by extraneous stimuli. Stimuli that served as good disinhibitors were generally effective external inhibitors. If one classifies the houselight presentations in our experiments as examples of "extraneous stimuli," then the present results corroborate Pavlov's conclusions about the differential effects of such stimuli on well established vs extinguished behavior. Furthermore, they support the action of Mechanism 3 proposed in the Discussion of Experiment III: Houselight presentations reinstate extinguished behavior through an inhibition of an inhibition mechanism.

Other explanations of external inhibition and disinhibition, e.g., in terms of stimulus generalization decrement (Denny, 1971) or neuronal discrepancy models (Sokolov, 1963), probably apply as well as Pavlov's to our houselight results. Further work on disinhibition will require additional analysis of such terms as "discrepancy" and "extraneous stimulus." We have used the latter term in the loose sense implied by Pavlov and Skinner: An extraneous stimulus is some easily discriminated environmental change that does not itself evoke responses resembling those being measured. In our work, presentations of the houselight did seem to fulfill this definition. They were clearly discriminable and did not produce keypecking or approach movements toward the houselight source or the key.

Several writers (cf. Brimer, 1972; Pavlov, 1927; Skinner, 1938) have suggested that evidence of disinhibition may provide one of the best criteria for deciding whether inhibition is operating in a particular situation and whether, in fact, the concept of inhibition is useful in an analysis of behavior. For example, in opposing Pavlov's views on the inhibitory character of extinction, Skinner wrote about the "supposed phenomenon of 'disinhibition' in which a reflex in the course of extinction is said to be released from inhibition by an extraneous formulation given above [1938, p.97, italics ours]."We feel we have satisfied Skinner's own criteria for abandoning the single- (excitatory) factor formulation and for including the term "inhibition." In the houselight experiments we found "a stimulus which does not itself affect the response in question [Skinner, 1938, p. 17]." We demonstrated that this stimulus may have either a positive (disinhibition) or negative (external inhibition) effect in an operant conditioning task.

There are two other points about our experiments that seem to merit additional consideration. The first and most important of these involves interpretation of the response facilitations produced by trial-tempo increments. This result was consistent with our expectations from neurophysiological studies (Bruner \& Kennedy, 1970) concerned with the problem of habituation, studies that provided the original impetus for the series of experiments described in this report. The neurophysiological evidence available at the present time indicates that habituation is the result of an inhibitory process. Our early interpretation of the trial-tempo effects on extinguished behavior suggested that the increments in responding during $5-\mathrm{sec}$ ITI blocks were not the result of an inhibition of an inhibition; they can be attributed to the relatively high excitation/inhibition ratio shortly after a trial. In other words, as in analysis of temporal effects in work on habituation, two opposing processes are presumed to interact and they dissipate differentially as a function of time since the last stimulus (trial). Such an account would predict generally greater extinction responding on 5 -sec ITI blocks than on 25-sec blocks, regardless of the prior training conditions-as was actually observed in our comparison of Experiments II-III. This account would also suggest that different results might have been obtained in our experiments if Ss were shifted, for example, from 25- to $125-\mathrm{sec}$ ITIs or from 125 - to 25 -sec ITIs, rather than to or from the very short $(5-\mathrm{sec})$ ITIs we used. Research with a variety of other ITI values (see Mackintosh, 1974, for a general review of the 
effects of ITI duration during acquisition and extinction) seems necessary to examine the generality of our trial-tempo results and to evaluate the above interpretation.

We do not believe that Sokolov's neuronal-template notion or Denny's generalization decrement formulation can handle all of the trial-tempo effects. At least on the surface, Pavlov's approach also seems to experience difficulty with the same findings. However, he did stress the importance of excitatory and inhibitory aftereffects of prior trials upon subsequent trials, and a number of his experiments analyzed responding to positive and negative conditioned stimuli as a function of the time since the last trial. It is probably true that temporal effects of the kind reported in our extinction research, which correspond to those obtained in studies of habituation, could be accommodated more easily within a Pavlovian framework than within the alternative formulations mentioned above.

A qualification must be added to our comments about interpretation of trial-tempo effects. Although all the data obtained from our extinction procedures did support the notion that massing of trials has a generally facilitative effect (rather than producing inhibition of an inhibition), the data obtained during acquisition (Experiment V) were inconsistent with this notion. A change from 25- to 5-sec ITIs during continued reinforcement of trial behavior had, if anything, a weakening effect on keypecking. This outcome suggests that all the formulations outlined above are incomplete in some important respects.

A second major point involves our finding that the decrements in intermittently reinforced behavior produced by houselight presentations during ITIs were dependent on the outcome of the immediately preceding trial. Such houselight presentations reduced behavior on trials that followed nonreinforced trials, but did not affect behavior on trials that followed reinforced trials. These effects were small but consistent. Pavlov, on the other hand, obtained evidence of external inhibition in situations in which every CS was followed by US (he rarely used schedules of intermittent reinforcement in his work). The details of Pavlov's procedures were so different from ours that we cannot comment constructively on the relationship of our results to his. The results do suggest, however, that the intermittency of reinforcement may prove an important determinant of the magnitude of response reduction during acquisition, and of response recovery during extinction, produced by an extraneous stimulus. In fact, Brimer's (1970b) findings, obtained in a free-operant situation rather than on a discrete-trial procedure as used here, indicated that behavior during extinction following intermittent reinforcement is more susceptible to disinhibition than behavior during extinction following reinforcement of every response.

\section{REFERENCES}

Amsel, A. Partial reinforcement effects on vigor and persistence. In K. W. Spence and J. T. Spence (Eds.), The psychology of learning and motivation. Vol. 1. New York: Academic Press, 1967. Pp. 1-65.

Boakes, R. A. Response decrements produced by extinction and by response-independent reinforcement. Journal of the Experimental Analysis of Behavior, 1973, 19, 293-302.

Boakes, R. A., \& Halliday, M. S. Inhibition and learning. New York: Academic Press, 1972.

Bolles, R. C. Species-specific defense reactions. In F. R. Brush (Ed.), Aversine conditioning and learning. N $\mathrm{ew}$ York: Academic Press, 1971. Pp. 183-233.

Brimer, C. J. Disinhibition of an operant response. Learning \& Motivation, 1970a, 1, 346-372.

Brimer, C. J. Inhibition and disinhibition of an operant response as a function of the amount and type of prior training. Psychonomic Science, 1970b, 21, 191-192.

Brimer, C. J. Disinhibition of an operant response. In $R$. A. Boakes and M. S. Halliday (Eds.), Inhibition and learning. New York: Academic Press, 1972. Pp. 205-227.

Bruner, J., \& Kehoe, J. Long-term decrements in the efficacy of synaptic transmission in molluscs and crustaceans. In G. Horn and R. A. Hinde (Eds.), Short-term changes in neural activity and behavior. Cambridge, England: Cambridge University Press, 1970. Pp. 323-359.

Bruner, J., \& Kennedy, D. Habituation: Occurrence at a neuromuscular junction. Science, 1970, 169, 92-94.

Denny, M. R. A theory of experimental extinction and its relation to a general theory. In $H$. Kendler and J. T. Spence (Eds.), Essays in neobehaviorism. New York: Appleton-Century-Crof ts, 1971. Pp. 43-67.

Horn, G., \& Hinde, R. A. Short-term changes in neural activity and behavior. Cambridge, England: Cambridge University Press, 1970.

Mackintosh, N. J, The psychology of animal learning. New York: Academic Press, 1974.

Pavlov, I. P. Conditioned reflexes. London: Oxford University Press, 1927.

Scull, J. W. The Amsel frustration effect: Interpretations and research. Psychological Bulletin, 1973, 79, 352-361.

Skinner, B. F. The behavior of organisms. New York: Appleton-Century-Crof ts, 1938.

Sokolov, Y. N. Perception and the conditioned reflex. New York: Pergamon Press, 1963.

Thompson, R. F., \& Spencer, W. A. Habituation: A model phenomenon for the stud $y$ of neuronal substrates of behavior. Psychological Review, 1966, 73, 16-43.

\section{NOTES}

1. In several pilot studies we have been uniformly unsuccessful in attempts to obtain reliable recovery of extinguished behavio by means of various novel auditory stimuli (different intensities and frequencies of clicks, tones, or noises) presented during the ITt. Perhaps novel sounds are very likely to elicit species-specific defense (flight) reactions (Bolles, 1971) in pigeons, which are incompatible with keypecking.

2. We have also conducted an experiment in which only one presentation of the houselight occurred during each 25-sec ITI, after acquisition and initial extinction under 25-sec ITIs. For seven Ss the 5-sec houselight illumination started $20 \mathrm{sec}$ before the next trial was due, whereas for eight $S$ s it started $10 \mathrm{sec}$ before; in other words, either one of the two houselight presentations given during the ITI in the test sessions of Experiment IV was omitted, depending on the group. Both types of houselight condition produced a three-or fourfold increase in trial responding compared to alternated blocks without houselights. Therefore, the insertion of a single houselight within the 25-sec ITI produced as big a facilitative effect on extinguished operant behavior as did presentation of two houselights in Experiment IV. The rate or number of houselight presentations during a 25-sec ITI may not be crucial; a single one seems as effective as two. In all these experiments with houselights (including Experiment IV), recovery of trial responding was generally much more immediate than when trial-tempo shift was made. Keypecking often returned on the very first trial after a houselight had occurred during the ITI.

(Received for publication February 21, 1974; revision accepted May 14, 1974.) 